\title{
Application of Material Balance Equations of Multicompartment Gas Reservoirs in YC Gas Reservoir
}

\author{
Quan-Hua Huang ${ }^{1,}$, Chong Chen ${ }^{1, b}$, Lang Yin ${ }^{2, c}$, \\ Tong Liu ${ }^{1, d}$ and Tao Fang ${ }^{3, e}$ \\ ${ }^{1}$ State Key Laboratory of Oil \& Gas Reservoir Geology and Exploitation, Southwest Petroleum \\ University, Chengdu, Sichuan Province, People's Republic of China \\ ${ }^{2}$ Research Institute of Engineering Technology, Sinopec Southwest oil and gas field Company, \\ Deyang, Sichuan Province, People's Republic of China \\ ${ }^{3}$ CNOOC China Limited, Tianjin Branch, Tianjin Province, People's Republic of China \\ a swpuhqh@126.com, bchenchenchong@126.com, ${ }^{\mathrm{c}} 15922678513 @ 163 . c o m$, \\ d245002817@qq.com, 'fangtao5@cnooc.com.cn
}

\begin{abstract}
Keywords: compartmented gas reservoir, material balance, fault block, mathematical model
\end{abstract}
Abstract. A compartmented gas reservoir is defined as a reservoir involving two or more distinct blocks in hydraulic communication. A common one is a fault block gas reservoir separated into different fault blocks by partially sealing faults.

The fault plane in fault block gas reservoir works as the migration pathway of oil and gas sometimes, which makes the determination of reservoir pressure and dynamic reserves as well as remaining reserves complicated. Hence, in order to accomplish the goal of producing gas fields efficiently, it is necessary to have further study on the determination of reservoir pressure and evaluation methods of dynamic reserves, which can especially lay basis for the establishment of sequent development or adjustment program.

This paper establishes the mathematical model of multicompartment gas reservoirs and derives the corresponding material balance equations (MBEs) according to material balance. Then Newton-Raphson iteration scheme is employed to solve these equations. This model can be used not only for history matching, but also for performance prediction. An example is presented to analyze how transmissibility, gas initially in place (GIIP), gas production rate and commissioning time of the nonproducing reservoir affect the $\mathrm{P} / \mathrm{Z}$ behavior. The practical application of this method proves the method to be applicable. The change in influx and instantaneous flow rate between blocks can be quantitatively expressed by this method as well. Thus, producing degree of the nonproducing reservoir can be determined, which would be helpful to reduce costs and improve economic efficiency.

\section{Introduction}

Fault block gas reservoirs, as one kind of the main structural gas pools , are rather commonly found in oil and gas area in East China and South China Sea where so many faults develop. The fault plane in fault block gas reservoirs works as the migration pathway of oil and gas sometimes, while it performs as an obstacle at times[1]. When it acts as the former one, oil or gas can flow laterally or vertically, i.e. the producing reserves between different reservoir compartments or layers during the production run are employed mutually, so the determination of reservoir pressure, dynamic reserves and remaining reserves of gas reservoir becomes complicated. There are many methods of performance analysis. Material balance method is the most common one of those.

Firstly employing material balance method in 1989, Hower and Collins[2] established the model of compartmented gas reservoirs, and they proposed the analytical solutions of that. They were adjustable to the conditions of constant gas production rate, volumetric depletion and constant gas properties. However, the results could reflect the basic depleted characteristics of that kind of gas reservoir clearly. In 1991, Lord and Collins[3] applied MBE to a multicompartment system. They formulated differential equations of that and solved them by mathematics. However, no specific details of 
implementation of this method were given. Then Lord et al. extended the MBE method and applied it to the compartmented gas reservoir in Frio Layer in South Texas.

In 1993, aimed at the features of unbalanced exploitation in low-permeability gas reservoirs, Gao and Zhang et al.[4,5,6,7] founded a new dynamic prediction model of constant volume gas reservoirs: material balance of dual-compartment reservoirs. This model took the pressure difference and gas influx between high withdrawal area and stripper area into account, and it can be used to analyze production performance and variation of the supplied gas between blocks under different well patterns and development indexes.

In 1996, the multicompartment gas reservoir model was applied to single tight gas reservoirs by Payne[8]. Payne solved the MBE by explicit method; in the meanwhile, he ignored fluid exchange between boundaries and change in gas properties during a time step. For the determination of crossflow between compartments, the calculation procedure proposed by Payne is so easy that we can compute it directly by utilizing EXCEL. However, adopting explicit procedure as well as the use of pressure-squared approximation may result in unacceptable errors.

In 1999, after summarizing and analyzing the pros and cons of MBEs by Hower, Lord and Payne, J.Hagoort and R.Hoogstra[9] put forward the integral form of MBEs of dual-compartment gas reservoirs and used the implicit iteration procedure to solve them. They also summarized how crossflow between reservoir compartments, gas reservoir size and gas production rate influenced $\mathrm{P} / \mathrm{Z}$ behavior. The numerical methods were so practicable because of its simplicity and efficiency. But they just gave MBEs of dual-compartment gas reservoirs. The MBEs of multicompartment gas reservoirs with gas influx and efflux remain to be studied in details.

Employing rigorous mathematical methods, N.M.A. Rahman and A.K. Ambastha[10] built up 3D differential model of a compartmented gas reservoir in 2000, and integral transform method was used to resolve those equations. Finally, the detailed characteristics of crossflow between reservoir compartments and the rigorous solution of reservoir pressure in space and time were obtained.

Liu, Lu and Wang[11] proposed the calculation of reserves of reservoir compartments , which are separated from compartmented gas reservoirs with water in 2007. They involved the effect of water aquifer into the MBEs, and they utilized apparent geologic reserve methods to calculate cumulative gas influx and the reserves of the separated reservoir compartments after simply changing the form of those equations. It was an easy method and could be completed in EXCEL. However, there are several unknowns, so multiple solutions of the MBEs may lead to poor reliable results.

According to material balance, this paper establishes a new model of dual-compartment gas reservoirs, considering gas influx and efflux between compartments, and presents MBEs of that. Then it is readily extended to multicompartment gas reservoirs with gas influx and efflux. Newton-Raphson iteration scheme is adopted to solve this kind of model. Combined with an example, the sensitivity of several parameters in MBEs is also analyzed. After comparing the results of the example, we can find that this model is applicable to such a complex and compartmented gas reservoir. The gas influx and efflux between different reservoir compartments can be determined according to this model, and then further make sure whether we perform actual drilling and development in the stripper areas, which contributing to improving development effectiveness.

\section{Modeling of multicompartment gas reservoirs}

The physical model of dual-compartment gas reservoirs is shown schematically in Fig.1. This model consists of two porous and permeable reservoir compartments, with a permeable barrier dividing them. They contain gas and water, and they were thought as storage tanks at uniform pressure and temperature. Whatever the gas is dry gas or wet gas, the gas properties in these two reservoir compartments are approximately the same.

The assumption that compartment 1 and compartment 2 cannot be exploited simultaneously is made. 


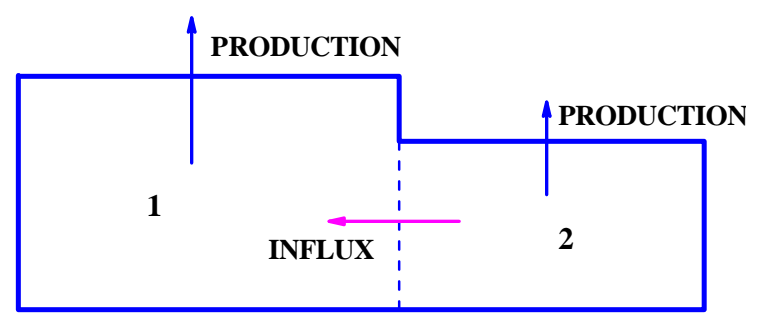

Fig.1 Schematic representation of a typical compartmented gas reservoir consisting of two reservoir compartments separated by a permeable boundary

The MBEs of the dual-compartment gas reservoir can be coupled to each other through cumulative gas influx or efflux.

$$
\left\{\begin{array}{l}
\frac{P_{1}}{Z_{1}}\left[1-C_{e}\left(P_{1 i}-P_{1}\right)\right]=\frac{P_{1 i}}{Z_{1 i}}\left(1-\frac{G_{p 1}-G_{p 12}}{G_{1}}\right) \\
\frac{P_{2}}{Z_{2}}\left[1-C_{e}\left(P_{2 i}-P_{2}\right)\right]=\frac{P_{2 i}}{Z_{2 i}}\left(1-\frac{G_{p 2}+G_{p 12}}{G_{2}}\right)
\end{array}\right.
$$

Where

$$
G_{p 12}=\int_{0}^{t} q_{12} d t ; q_{12}=T_{\mathrm{r} 12} \frac{T_{s c} Z_{s c}}{P_{s c} T}\left(m_{2}-m_{1}\right)
$$

Similarly, the general MBEs of multicompartment gas reservoirs with $\mathrm{n}$ reservoir compartments can be readily expressed as follows.

$$
\left\{\begin{array}{l}
\frac{P_{1}}{Z_{1}}\left[1-C_{e}\left(P_{1 i}-P_{1}\right)\right]=\frac{P_{1 i}}{Z_{1 i}}\left(1-\frac{G_{p 1}-G_{p 12}-G_{p 13} \mathrm{~L} \mathrm{~L}-G_{p 1(n-1)}-G_{p 1 n}}{G_{1}}\right) \\
\frac{P_{2}}{Z_{2}}\left[1-C_{e}\left(P_{2 i}-P_{2}\right)\right]=\frac{P_{2 i}}{Z_{2 i}}\left(1-\frac{G_{p 2}+G_{p 12}-G_{p 23} \mathrm{~L} \mathrm{~L}-G_{p 2(n-1)}-G_{p 2 n}}{G_{2}}\right) \\
\mathrm{L} \mathrm{L} \\
\frac{P_{n-1}}{Z_{n-1}}\left[1-C_{e}\left(P_{(n-1) i}-P_{n-1}\right)\right]=\frac{P_{(n-1) i}}{Z_{(n-1) i}}\left(1-\frac{G_{p(n-1)}+G_{p 1(n-1)}+G_{p 2(n-1)} \mathrm{L} \mathrm{L}+G_{p(n-2)(n-1)}-G_{p(n-1) n}}{G_{3}}\right) \\
\frac{P_{n}}{Z_{n}}\left[1-C_{e}\left(P_{n i}-P_{n}\right)\right]=\frac{P_{n i}}{Z_{n i}}\left(1-\frac{G_{p n}+G_{p 1 n}+G_{p 2 n} \mathrm{~L} \mathrm{~L}+G_{p(n-2) n}+G_{p(n-1) n}}{G_{3}}\right)
\end{array}\right.
$$

Where

$$
G_{p i j}=\int_{0}^{t} q_{i j} d t ; q_{i j}=T_{\mathrm{r} i j} \frac{T_{s c} Z_{s c}}{P_{s c} T}\left(m_{j}-m_{i}\right) ; m_{i}=2 \int_{0}^{p} \frac{\bar{p}_{i}}{u_{i} z_{i}} d p ; m_{j}=2 \int_{0}^{p} \frac{\bar{p}_{j}}{u_{j} z_{j}} d p
$$

In the above equations, crossflow between reservoir compartments $\left(q_{i j}\right)$ is governed by Darcy's law in the form of pseudo-pressure, which takes full account of the pressure dependence of gas properties. Here we calculate the pseudo-pressure during the exploitation by trapezoidal quadrature formula. In case that gas influx and efflux between different reservoir compartments exists, the flow direction of fluids is primarily decided by pseudo formation pressure. Here, we are provided that positive $q_{i j}$ means that gas flows from reservoir $\mathrm{j}$ into reservoir $\mathrm{i}$, and negative $q_{i j}$ means that gas flows from reservoir $\mathrm{i}$ into reservoir $\mathrm{j}$.

The initial value conditions of these equations are that the initial reservoir pressure of each gas reservoir compartment is the same before the start of production. We assume that the formation temperature remains constant throughout the entire production process, i.e. isothermal decompression production.

$t=0: P_{1}=P_{2}=\mathrm{L} \mathrm{L}=P_{n}=P_{i} ;$ and $T_{1}=T_{2}=\mathrm{L} \mathrm{L}=T_{\mathrm{n}}=T_{i}$

Here, $n$ means the numbers of reservoir compartments. 
After production, each reservoir pressure and crossflow between reservoir compartments are both functions of cumulative gas production and recovering time, so production profiles of different reservoir compartments will present different pressure drop and change in gas flow.

$$
t>0: G_{p 1}=G_{p 1}(t) ; G_{p 2}=G_{p 2}(t) \perp \mathrm{L} ; G_{p n}=G_{p n}(t) \text {, and } T_{1}=T_{2}=\mathrm{L} \mathrm{L}=T_{\mathrm{n}}=T_{i}
$$

Here, $n$ means the numbers of reservoir compartments.

Therefore, for the producing gas reservoir, if the variation of reservoir pressure is known, we can substitute actual production profiles of each reservoir into the equations above. Supposing that one or several parameters are unknown, such as geological reserves and transmissibility, gas influx or efflux between reservoir compartments can be determined by adjusting these parameters to fit the observed reservoir pressures.

Simultaneously, for the nonproducing gas reservoir, we can predict reservoir pressure variation with recovering time and when and how much natural gas supplies with each gas reservoir compartment.

There are several parameters referred to the MBEs above. They are Z-factor, gas viscosity, volume factor, pore compressibility and formation water compressibility. DPR method and the correlation of Lee et al. can be chose to calculate Z-factor and gas viscosity respectively. Volume factor of natural gas can be obtained according to pressure, temperature, Z-factor and specified standard condition. Pore compressibility can be computed in the light of empirical formula describing the relationship of $C_{p}$ versus $\phi$. Formation water compressibility can be determined by the expression presented by $\mathrm{McCaiB}[12]$.

\section{Solution of the model}

Newton-Raphson iteration scheme of nonlinear equations is required to solve the MBEs above. For an appropriate iterative initial value, the degree of convergence of this scheme is second-order. Here the initial value is initial reservoir pressure, often acquired by actual measurement. So it is reliable and the equations are generally convergent. Taking the influence of pressure on natural gas properties into account, then the updated pressure by iteration is employed to calculate the physical parameters of natural gas. During an iteration cycle, the latest adjusted pressure is differentiated. Therefore, this scheme is an implicit method.

Suppose that instantaneous gas influx during a time step is linear to time, then cumulative influx during a time step $(\Delta t)$ can be calculated by the expression below.

$$
G_{p i j}(t+\Delta t)=G_{p i j}+\frac{1}{2}\left[q_{i j}(t)+q_{i j}(t+\Delta t)\right] \Delta t
$$

It can be applied to solve the equations at successive time step. The initial estimate is initial reservoir pressure $\left(P_{i}\right)$. The initial estimate $\left(P_{B}\right)$ at a new time step is regarded as the convergence pressure at the last time step. When the corrected pressure is smaller than an allowable deviation value, such as 0.001MPa, stop the iteration. The computer programming demonstrated that Newton-Raphson iteration scheme is fast and steady. Pressure would converge within 3-8 iterations.

The degree of deviation of the calculated reservoir pressure mainly depends on accuracy of the calculated crossflow between gas reservoir compartments and the size of time step9. If there does not exist crossflow between gas reservoir compartments, there is no constraint to the size of time step either. It is needed to halve or double time step size to check the sensitivity of these equations to the size of time step. In the light of J.Hagoort et al, change in pressure during a time step should be less than $2 \%$ of the initial reservoir pressure.

As mentioned above, material balance equation method can be used for production prediction as well as history matching. In a certain iterative domain, computer programming can automatically adopt nonlinear regression technique to complete history matching according to method of nonlinear least squares. 


\section{Sensitivity analysis of computationl parameters}

Generally speaking, there are more potential unknowns than given data in the MBEs. That is to say, there are too less equations to derive unknowns, which is a big problem throughout the petroleum engineering field. Even numerical simulation is not able to settle this problem. It just added some potential unknowns to sparse equations, such as geometry, porosity, permeability and relative permeability. Just because of the multiple solutions and uncertainties of the MBEs, it is significantly essential to analyze and determine the degree of the influence of parameters in MBEs on the results.

Taking Case 1 in SPE 57655 for example here, called Base Case, we will discuss the main characteristics of pressure depletion and gas influx of the dual-compartment gas reservoir. Table 1 lists the relevant reservoir data and gas properties of the Base Case. Research methods advanced by J.Hagoort were partially referred to. The results here are in accord with that in SPE 57655. We enlarged or reduced some important parameters in MBEs again, involving geological reserves, transmissibility and gas production rate. Then the results were calculated under those different conditions. In the meanwhile time, we analyzed how these parameters influenced the results.

Table 1 Basic data of the Base Case

\begin{tabular}{|c|c|c|c|}
\hline \multicolumn{2}{|l|}{ Standard Conditions } & \multicolumn{2}{|l|}{ Reservoir Data } \\
\hline Standard pressure $(\mathrm{MPa})$ & 0.101325 & GIIP of the producing reservoir $\left(10^{8} \mathrm{~m}^{3}\right)$ & 40 \\
\hline Standard temperature $\left({ }^{\circ} \mathrm{C}\right)$ & 0 & GIIP of the nonproducing reservoir $\left(10^{8} \mathrm{~m}^{3}\right)$ & 40 \\
\hline \multicolumn{2}{|l|}{ Gas Properties } & Initial reservoir pressure $(\mathrm{MPa})$ & 35 \\
\hline Gas gravity & 0.65 & Initial reservoir temperature $\left({ }^{\circ} \mathrm{C}\right)$ & 110 \\
\hline Pseudo-critical pressure ( $\mathrm{MPa})$ & 4.5 & Transmissibility $(\mathrm{md} \cdot \mathrm{m})$ & 100 \\
\hline Pseudo-critical temperature $(\mathrm{K})$ & 200 & Initial porosity, fraction & 0.15 \\
\hline \multicolumn{2}{|l|}{ Production Profile } & Initial water saturation, fraction & 0.25 \\
\hline Constant production $\left(10^{4} \mathrm{~m}^{3} / \mathrm{d}\right)$ & 70 & Pore compressibility $(1 / \mathrm{Mpa})$ & 0.0006 \\
\hline \multicolumn{2}{|c|}{ Information of Numerical Control } & Water compressibility $(1 / \mathrm{Mpa})$ & 0.0006 \\
\hline Time step (d) & 60 & & \\
\hline
\end{tabular}

Computer programming was employed to solve the $\overline{\mathrm{MBE}}$ above. The simulated production time of this typical case is 9000 days, i.e. 150 time steps, and the computing time was less than 10 seconds.

The results of the Base Case are presented in Fig.2. The solid lines in it are P/Z curves of the producing reservoir and the nonproducing reservoir. By comparison with that, the dotted lines, showing P/Z curves under two extreme conditions, are also included in Fig.2. One condition is the depletion development without gas flowing into the producing reservoir from the nonproducing reservoir, which means that transmissibility is 0 . The other is the depletion development with the assumption that the two reservoirs are fully connected, which means that transmissibility is infinitely great. The intercept of $\mathrm{P} / \mathrm{Z}$ curve and $\mathrm{Gp}$-axis is equal to the geological reserves of the producing reservoir for the former condition while the intercept of them is equal to the total geological reserves of the two reservoirs for the latter condition9.

We can learn from Fig. 2 that the slope of P/Z curve of the producing reservoir in the early development period is equal to the slope of the $\mathrm{P} / \mathrm{Z}$ straight line corresponding to transmissibility of 0 . After a short time, the $\mathrm{P} / \mathrm{Z}$ curve inclines to the $\mathrm{P} / \mathrm{Z}$ straight line corresponding to the infinite transmissibility. Then the system enters pseudo-steady state before long. The rate of pressure decline of the two reservoirs is approximately the same in this stage. The $\mathrm{P} / \mathrm{Z}$ curve corresponding to pseudo-steady state is nearly parallel to that corresponding to the infinite transmissibility9.

Fig. 3 described the relationship between cumulative gas production of the producing reservoir and instantaneous flow rate as well as cumulative gas influx from the nonproducing reservoir. The instantaneous flow rate enjoys its peak soon and pseudo-steady state flow regime develops. Under pseudo-steady state flow, both reservoirs contribute to the exploitation of the whole gas reservoir, and the contributions is propositional to its geological reserves. Hence, cumulative gas influx from the nonproducing reservoir is half of the total gas production of the producing reservoir in this paper. 
Besides, the instantaneous flow rate is propositional to the pseudo pressure difference of the two reservoirs on the basis of Darcy's law.

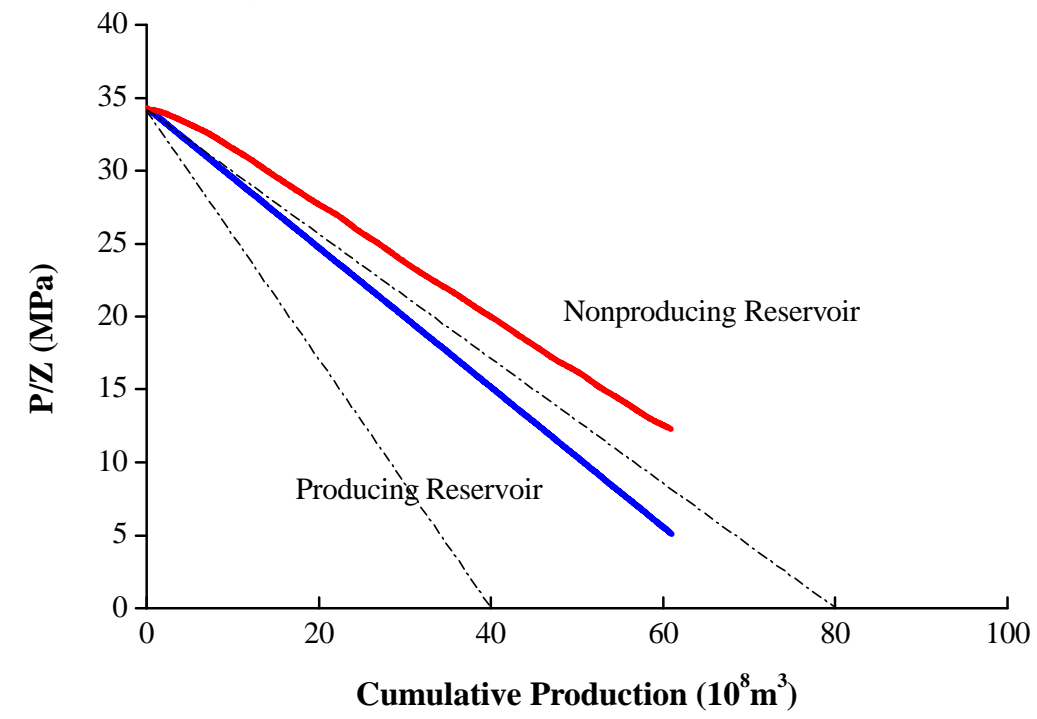

Fig.2 Base Case P/Z behavior of the producing and nonproducing reservoir

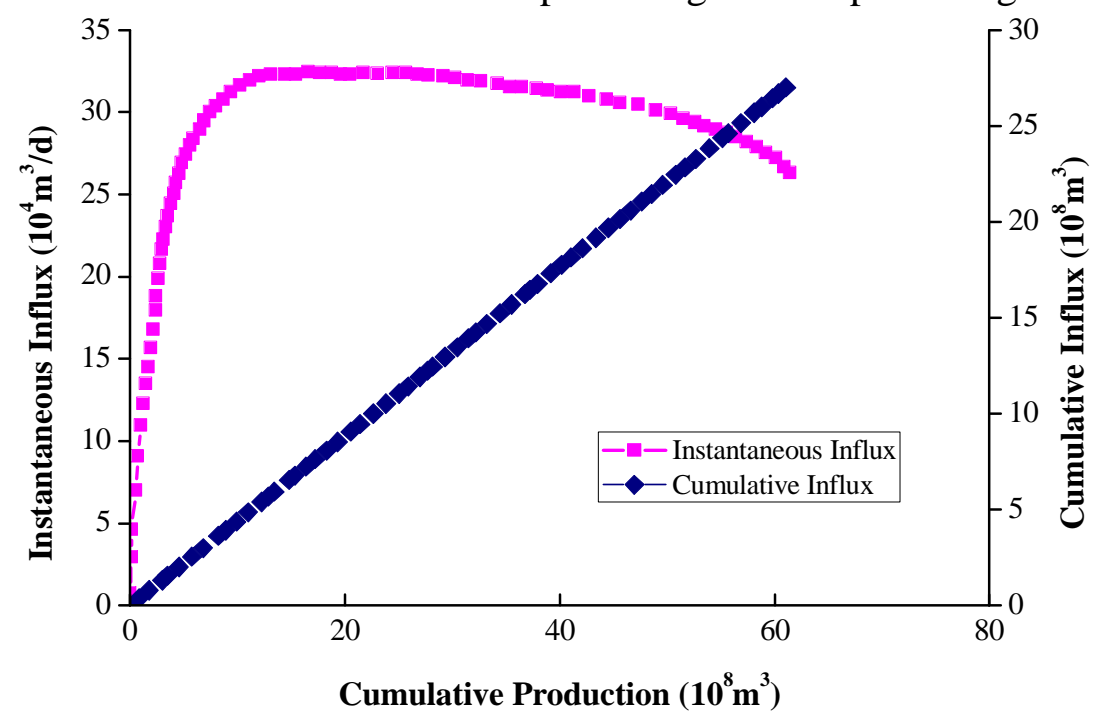

Fig.3 Base Case influx into the producing reservoir

Influence of Transmissibility

Transmissibility is an important parameter describing the connectivity between two reservoirs. The greater it is, the better percolation ability between reservoirs is and the more obvious the fault sealing is. Generally, it is hard to determine it by field test. However, the MBEs could be a preferable choice to solve it. P/Z curves and instantaneous flow rate curves under different transmissibility were respectively presented in Figs. 4 and 5.

As shown in Fig.4, the P/Z curve corresponding to transmissibility of 10 is close to that corresponding to transmissibility of 0 . The formation pressure of the two reservoirs keeps divergent until they are abandoned. It is apparent that pseudo-steady state flow regime cannot develop when transmissibility is small. When transmissibility is respectively 50, 100 and 200, the corresponding P/Z curves of both reservoirs incline to a straight line gradually. In other words, two fully connected reservoirs can be viewed as a single reservoir to be exploited when transmissibility is infinite.

According to Fig.5, it takes a relatively long time for the instantaneous flow rate corresponding to transmissibility of 10 to reach a maximum gradually, which is still relatively small. It would affect some parameters related to pressure, such as Z-factor, gas viscosity and volume factor, resulting in a sharp nonlinear relationship between flow rate and pressure drop finally. This phenomenon is similar to middle-later section of inflow performance curve of a gas well. The maximal instantaneous flow rate 
increases with the increment of transmissibility. However, the maximum will be $35 \times 10^{4} \mathrm{~m}^{3} / \mathrm{d}$, half of the total flow rate, at the very most.

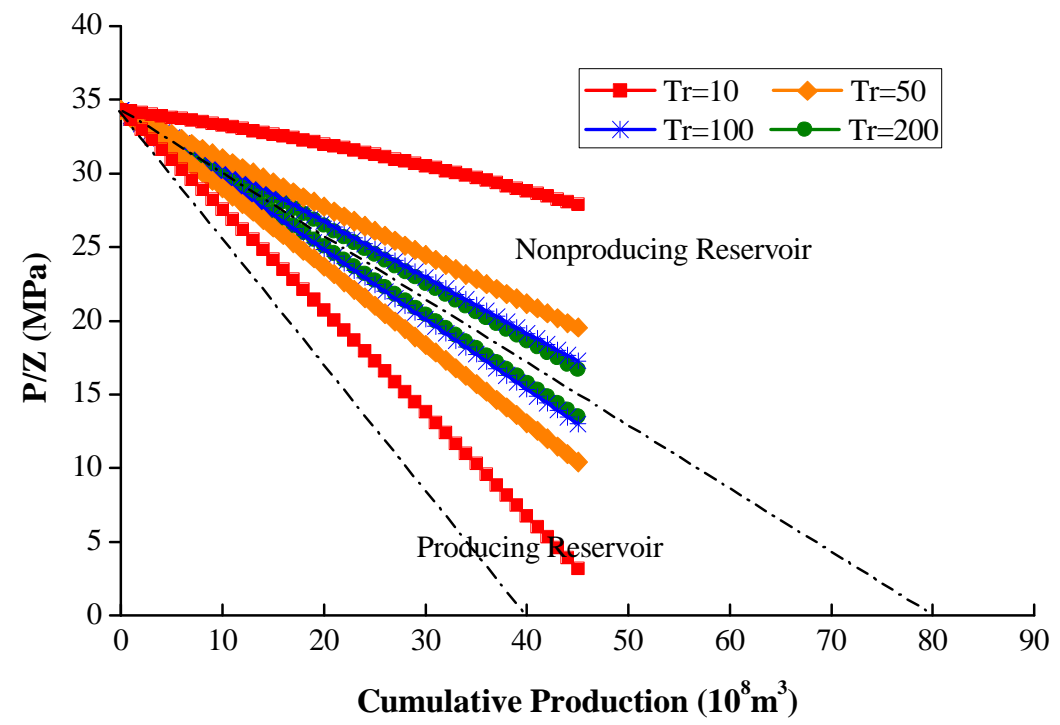

Fig.4 P/Z curves of the producing and nonproducing reservoir under different transmissibility

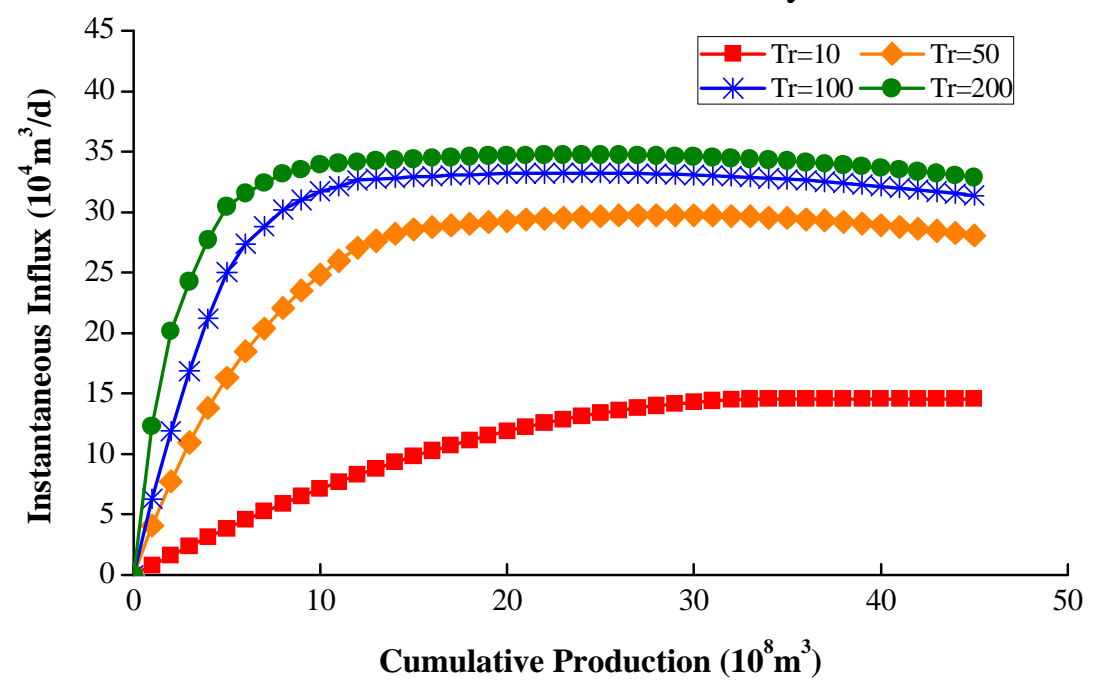

Fig.5 Instantaneous flow rate into the producing reservoir under different transmissibility

Influence of Geological Reserves

Figs. 6 and 7 show the results when geological reserves of the nonproducing reservoir are twice of that of the Base Case. Consequently, the depletion characteristics are identical with these of the Base Case quantitatively. The nonproducing reservoir contributes more to the total production as its geological reserves increase. So does the instantaneous flow rate. As a result of the increment of instantaneous flow rate, the pressure difference between the two reservoirs is larger than that of the Base Case.

Figs. 8 and 9 present the results when geological reserves of the nonproducing reservoir reduce by half of that of the Base Case. As a result of the reduction of instantaneous flow rate, the pressure difference between the two reservoirs is smaller than that of the Base Case. And the P/Z curve of the producing reservoir is close to that corresponding to infinite transmissibility.

In conclusion, under the same transmissibility and gas production rate, the larger geological reserves of the nonproducing reservoir are, the greater instantaneous flow rate is. The more evidently the pressure of the two reservoirs diverges, the lower recovery percent is, and vice versa. 


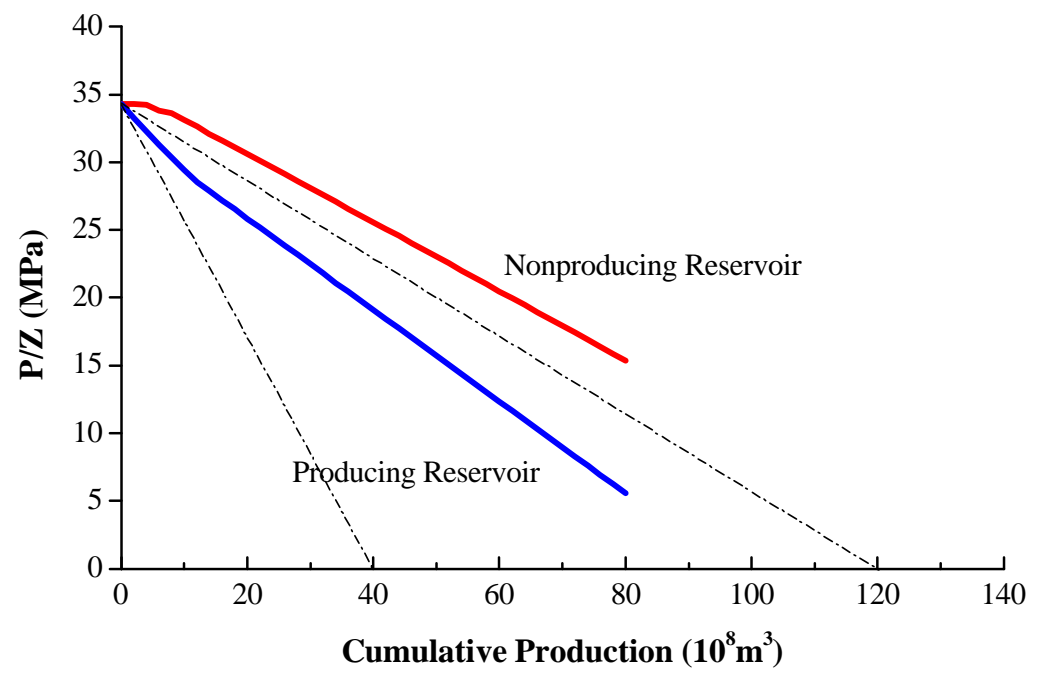

Fig.6 P/Z curves of both reservoirs for twice of Base Case geological reserves of the nonproducing reservoir

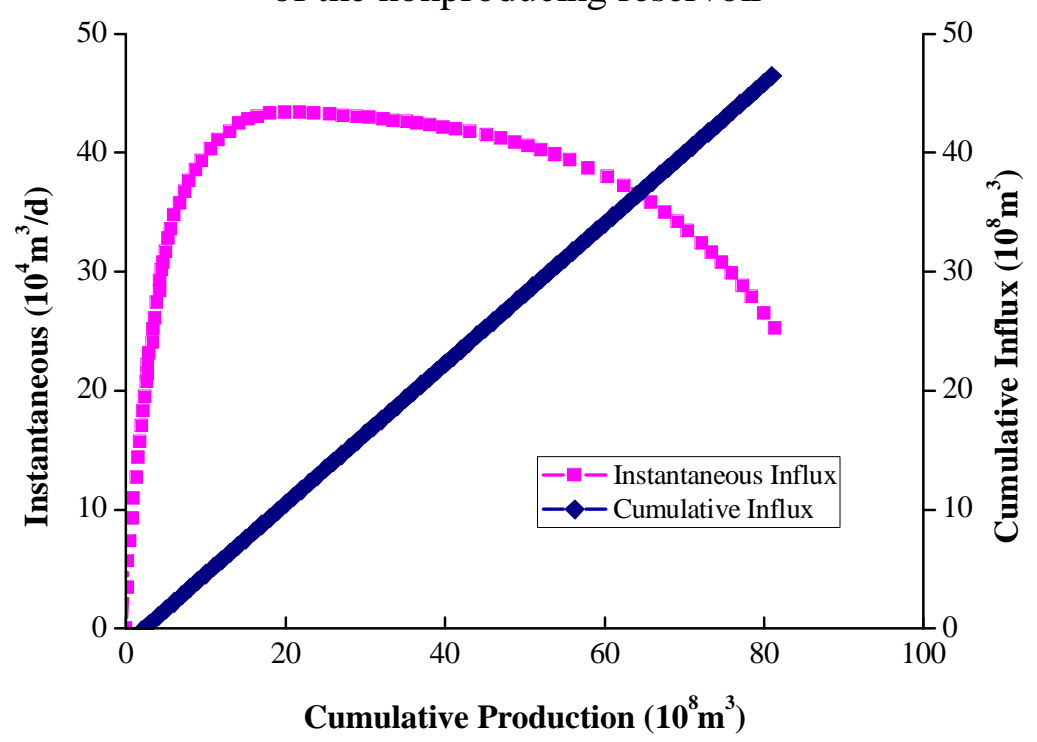

Fig.7 Influx into the producing reservoir for twice of Base Case geological reserves of the nonproducing reservoir

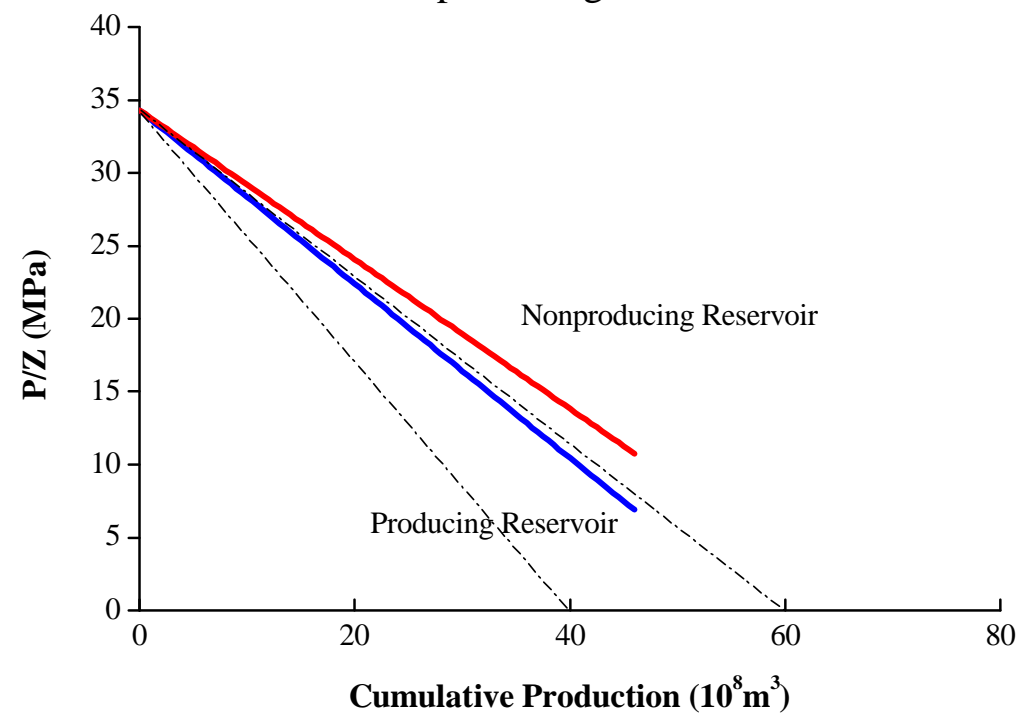

Fig. 8 P/Z curves of both reservoirs for half of Base Case geological reserves of the nonproducing reservoir 


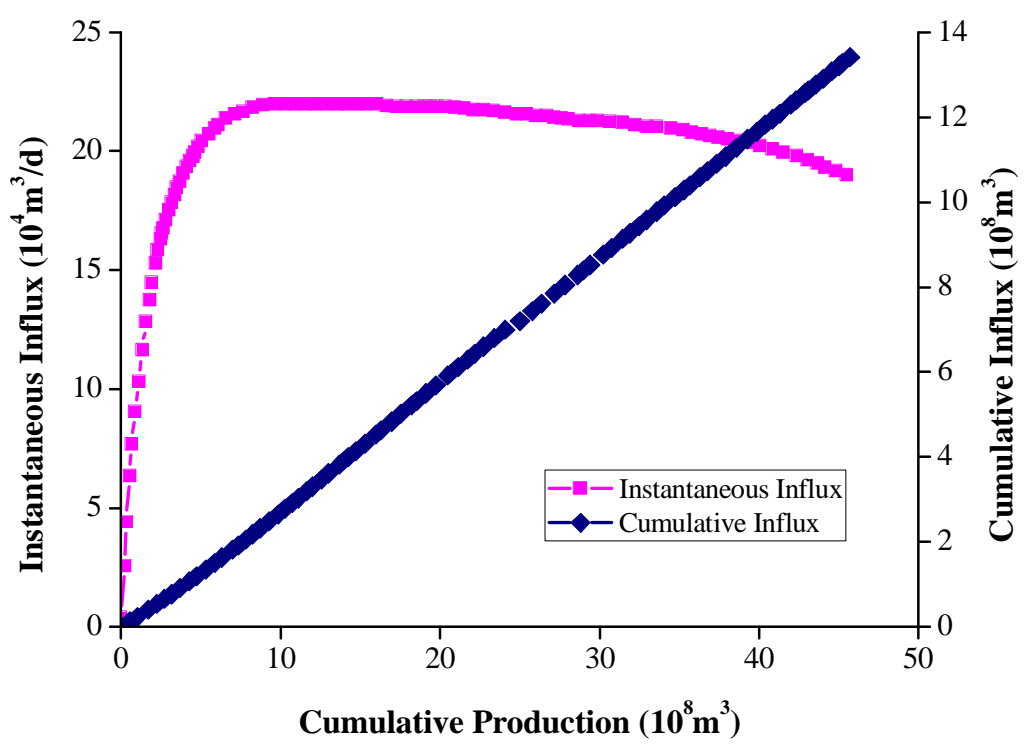

Fig.9 Influx into the producing reservoir for half of Base Case geological reserves of the nonproducing reservoir

Influence of Gas Production Rate

Fig.10 shows the results when gas production rate of the producing reservoir is half or twice of that of the Base Case.

In the circumstance of gas production rate reduction by half, the corresponding instantaneous flow rate would reduce to half of that of the Base Case, because instantaneous flow rate is linear to instantaneous flow rate under pseudo-steady state. Therefore, pressure difference between the two reservoirs is half of that of the Base Case, leading to the two curves being close to each other. They both incline to the $\mathrm{P} / \mathrm{Z}$ curve corresponding to infinite transmissibility. This implies that lowering gas production rate can enhance natural gas recovery for a gas reservoir under a given abandonment pressure.

On the other hand, in the circumstance of gas production rate doubling, cumulative gas production is twice of that of the Base Case within the same production time. The end of $P / Z$ curve of the producing reservoir approaches the $\mathrm{Gp}$-axis, so this reservoir can be abandoned nearly. However, there are still some certain reserves remaining to be exploited in the nonproducing reservoir. The follow-up research proves that continuous development contributes to improving gas recovery. Consequently, increasing gas production rate is conducive to develop gas reservoir more quickly. Large gas production rate and development of the nonproducing reservoir in advance are efficient and economical development methods for complex, offshore fault reservoir gas reservoirs with gas influx or efflux.

Fig.11 presents instantaneous flow rate of the nonproducing reservoir under different gas production rate. As showed, the lower gas production rate is, the smaller the instantaneous flow rate is, but the two reservoirs can enter pseudo-steady state ahead of time. When gas production rate is higher, the instantaneous flow rate is larger and the two reservoirs enter pseudo-steady state with a delay of time. What's more, instantaneous flow rate tends to decline when recovery percent reaches a certain higher value, similar to the production performance when transmissibility is small. That's because the pressure difference between the two reservoirs is inclined to increase in production tail and the influence of pressure on Z-factor, gas viscosity and volume factor becomes more and more significant, resulting in a nonlinear relationship between flow rate and pressure drop finally. At that time the fluids flow nearby the boundary does not follow Darcy's law. 


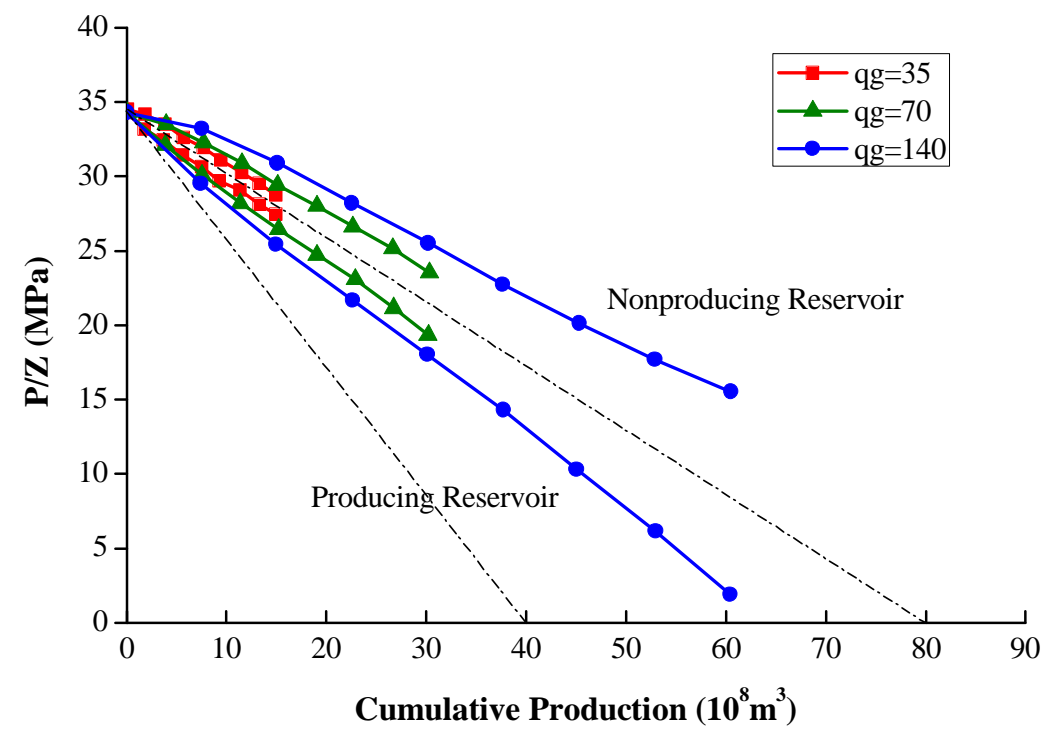

Fig.10 P/Z curves of both reservoirs under different gas production rates

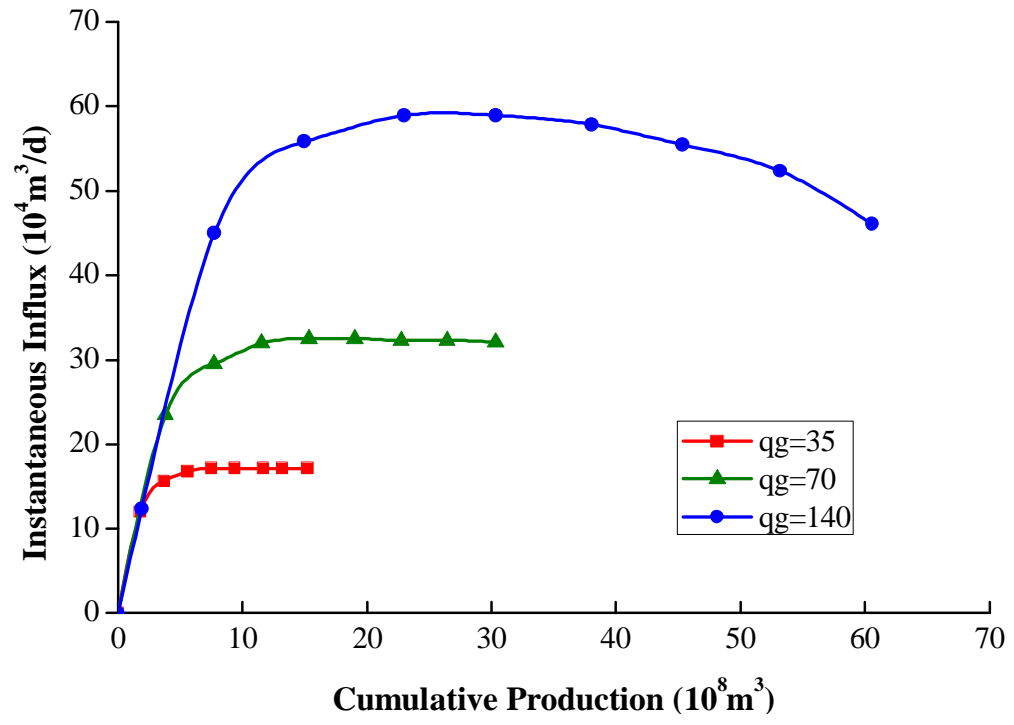

Fig.11 Instantaneous flow rate into the producing reservoir under different gas production rates

Influence of Commissioning Time of the Nonproducing Reservoir

Fig. 12 shows $\mathrm{P} / \mathrm{Z}$ curves of both reservoirs when the nonproducing reservoir is put into production after 5 to 20 years' development of the producing reservoir, with a time step of 5 years. In order to guarantee that the total production capacity remains unchanged after commissioning of the nonproducing reservoir, gas production rate of both reservoirs are half of that of the Base Case, $35 \times 104 \mathrm{~m} 3 / \mathrm{d}$. it can be found that whenever the nonproducing reservoir is put into production, gas recovery is approximately the same. In conclusion, the commissioning time of the nonproducing reservoir does not affect the gas recovery.

Fig.13 presents the variation of instantaneous flow rate with different commissioning time of the nonproducing reservoir. Owing to the same geological reserves and gas production rate of the two reservoirs, instantaneous flow rate into the producing reservoir decreases unexpectedly and finally it decreases to 0 when formation pressure of the two reservoirs strikes a balance. P/Z curves of both reservoirs draw near and coincide with each other at last. 


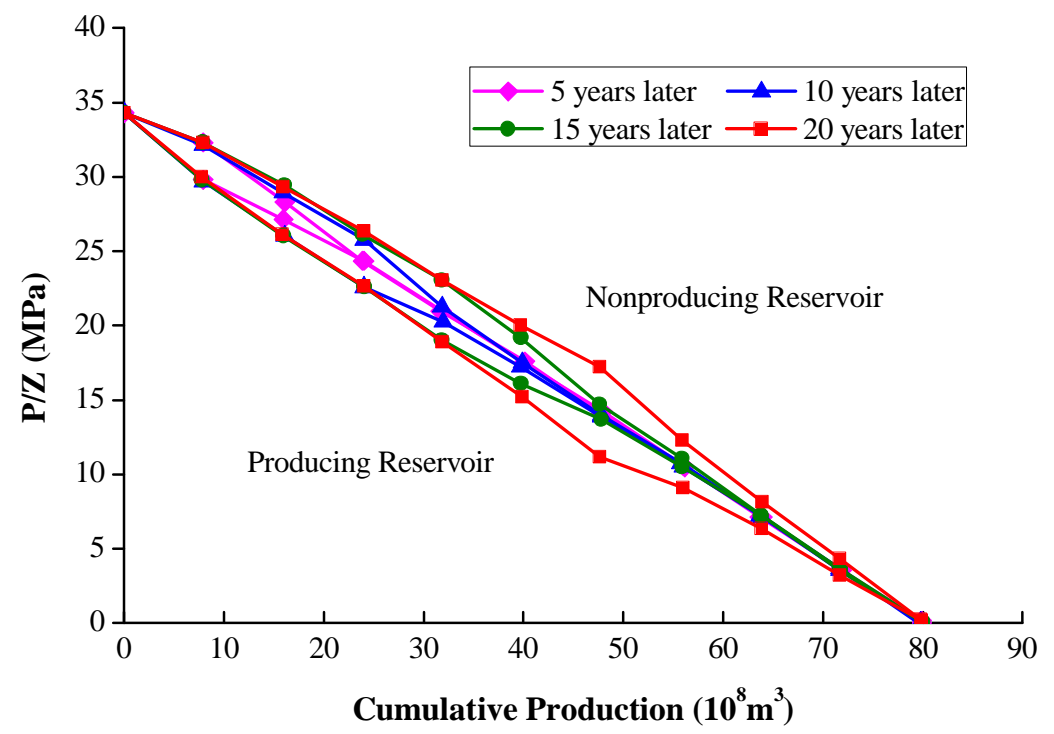

Fig. $12 \mathrm{P} / \mathrm{Z}$ curves of both reservoirs under different commissioning time

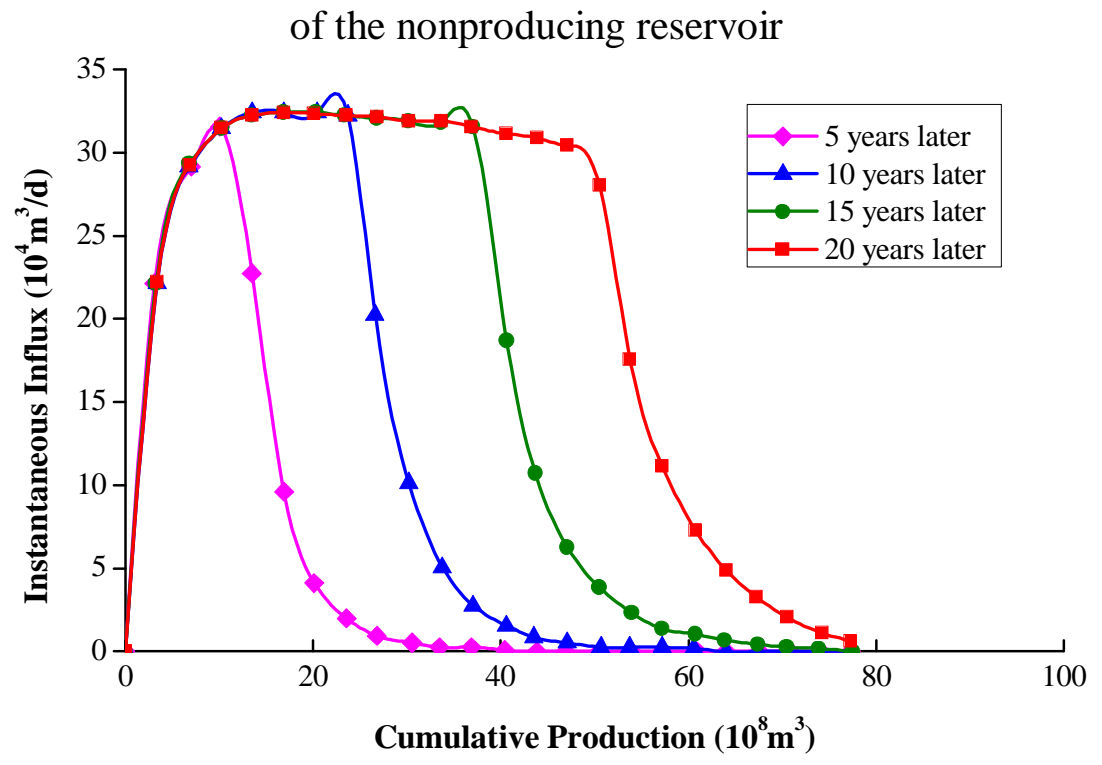

Fig.13 Curves of instantaneous flow rate into the producing reservoir under different commissioning time of the nonproducing reservoir

\section{Practical application and results}

A certain complex, offshore fault gas reservoir with total geological reserves of $930 \times 10^{8} \mathrm{~m}^{3}$ is taken for example. The average porosity of core is $13 \%$, with the maximum of $23 \%$. And the average permeability of core is $281 \times 10^{-3} \mu \mathrm{m}^{2}$, with the maximum of $4267 \times 10^{-3} \mu^{2}$, so the reservoir is a kind of low porosity-medium permeability $\sim$ medium porosity-high permeability reservoir. The average daily gas production rate is up to $677.52 \times 10^{4} \mathrm{~m}^{3}$. There are 11 production wells with 9 wells opening at present. X12 well and X7 well were shut in respectively in July, 2006 and in June, 2011 due to waterflooding. 


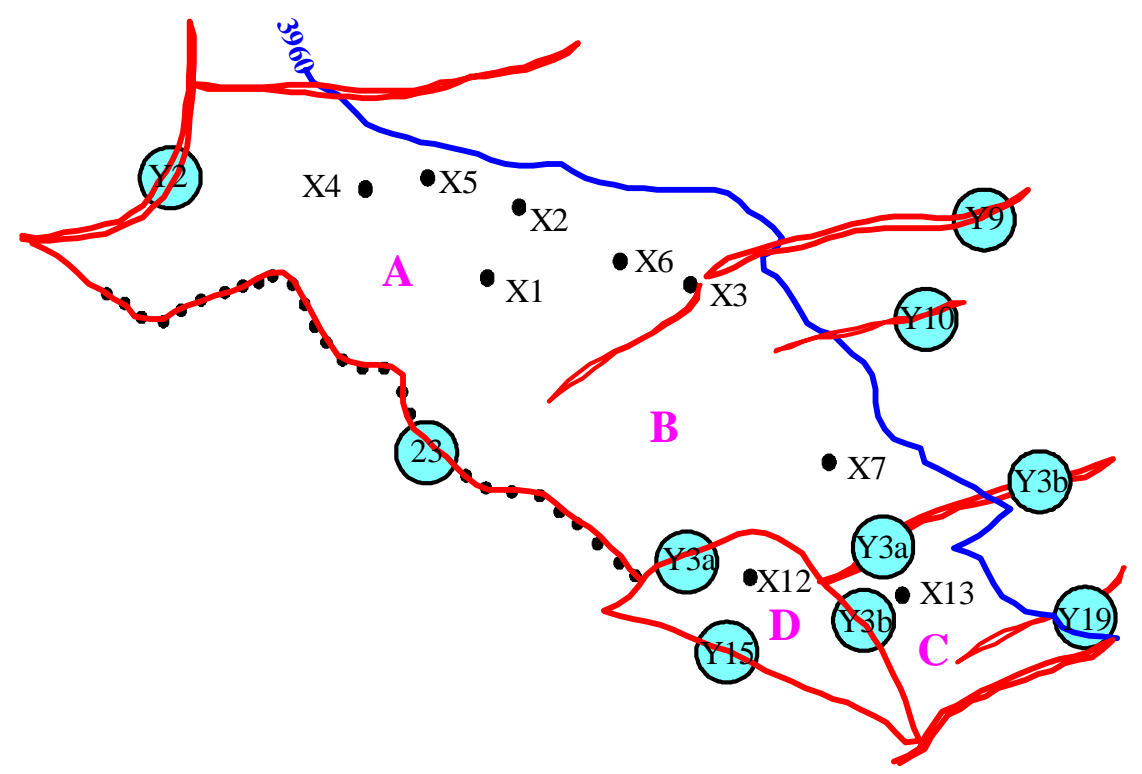

Fig.14 Wellarray map of a certain gas reservoir

As shown in Fig.14, the gas reservoir is divided into four blocks. Block A is separated from block B by a fault. Block B, C and D are separated by a T-shaped fault. Block A was the first one exploited, so the formation pressure of the other three blocks has dropped differently to some extent when they were put into production.

As presented in Table 2, reservoir producing degree of Block A is over 100\%, while that of Block B is relatively small and the average is $23.71 \%$. Therefore, Block B maybe employed by Block A. In addition, reservoir producing degree of Block $\mathrm{AB}$ is also more than $100 \%$, meaning that Block $\mathrm{CD}$ may be employed.

Table 2 Reservoir producing degree among these blocks

\begin{tabular}{|c|c|c|c|c|c|c|c|c|}
\hline \multirow[b]{2}{*}{ Well } & \multirow[b]{2}{*}{ Block } & \multirow[b]{2}{*}{$\begin{array}{l}\text { GIIP, } \\
10^{8} \mathrm{~m}^{3}\end{array}$} & \multicolumn{2}{|c|}{ Flowing material balance method } & \multicolumn{2}{|c|}{ Gas recovery method } & \multicolumn{2}{|c|}{$\begin{array}{l}\text { Oil reservoir influence function } \\
\text { method }\end{array}$} \\
\hline & & & $\begin{array}{c}\text { Dynamic reserves } \\
\left(10^{8} \mathrm{~m}^{3}\right)\end{array}$ & $\begin{array}{c}\text { Producing } \\
\text { degree ( \% } \\
\text { ) }\end{array}$ & $\begin{array}{l}\text { Dynamic } \\
\text { reserves ( } \\
\left.10^{8} \mathrm{~m}^{3}\right)\end{array}$ & $\begin{array}{c}\text { producing } \\
\text { degree ( \% } \\
\text { ) }\end{array}$ & $\begin{array}{r}\text { Dynamic } \\
\text { reserves ( } \\
\left.10^{8} \mathrm{~m}^{3}\right) \\
\end{array}$ & $\begin{array}{c}\text { Producing } \\
\text { degree ( \% ) }\end{array}$ \\
\hline $\mathrm{X} 1-\mathrm{X} 6$ & A & 360.38 & 527.877 & 146.48 & 530.50 & 147.07 & 530.13 & 147.10 \\
\hline $\mathrm{X} 7$ & B & 204.78 & 58.762 & 28.70 & 43.01 & 21.00 & 41.68 & 20.35 \\
\hline $\mathrm{X} 1-\mathrm{X} 7$ & $\mathrm{AB}$ & 565.16 & 586.64 & 103.80 & 573.01 & 101.39 & 571.806 & 101.18 \\
\hline $\mathrm{X} 13$ & $\mathrm{C}$ & 59.68 & 38.79 & 65.00 & 37.3 & 62.50 & 40.31 & 67.54 \\
\hline $\mathrm{X} 12$ & $\mathrm{D}$ & 23.54 & 7.627 & 32.40 & 5.6 & 23.79 & 5.58 & 23.70 \\
\hline \multicolumn{2}{|c|}{ Sum } & 648.38 & 633.057 & 97.64 & 615.91 & 94.99 & 617.693 & 95.27 \\
\hline
\end{tabular}

After analyzing the estimated formation pressure ( Table 3 ) and dynamic reserves, there mainly existed these cases as follows:

(1) Gas flows into Block A from Block B ( B $\rightarrow$ A );

(2) Gas flows into Block B or Block AB from Block C ( $\mathrm{C} \rightarrow \mathrm{B}$ or $\mathrm{AB})$;

(3) Gas flows into Block B or Block AB from Block D ( $\rightarrow$ B or AB ) ;

(4) Gas flows into Block D from Block C ( C $\rightarrow$ D ) . 
Table 3 The estimated formation pressure data

\begin{tabular}{|c|c|c|c|c|}
\hline Well & Date & $\begin{array}{c}\text { Estimated formation pressure } \\
(\mathrm{MPa})\end{array}$ & $\begin{array}{c}\text { Initial formation pressure ( } \\
\text { MPa })\end{array}$ & $\begin{array}{c}\text { Pressure drop ( } \\
\text { MPa ) }\end{array}$ \\
\cline { 1 - 2 } X7 & $2004-11-7$ & 26.34 & 38.54 & 12.21 \\
\hline X12 & $2005-1-1$ & 32.65 & 38.54 & 5.89 \\
\hline X13 & $2005-10-20$ & 37.42 & 38.54 & 1.12 \\
\hline
\end{tabular}

Here, the MBEs of multicompartment gas reservoirs can be reduced to MBEs of four-compartment gas reservoirs. Then this method was applied into these four blocks mutually influenced to analyze the change in formation pressure and producing reserves of these blocks. The main parameters to be referred to are in Table 4.

Table 4 Basic Data of the Reservoir

\begin{tabular}{c|c|c|c}
\hline \multicolumn{2}{c|}{ Standard Conditions } & \multicolumn{2}{c}{ Reservoir Data } \\
\hline Standard pressure ( MPa ) & 0.1013 & Initial reservoir pressure ( MPa ) & 38.55 \\
\hline Standard temperature ( ${ }^{\circ} \mathrm{C}$ ) & 15.5 & Initial reservoir temperature ( $\left.{ }^{\circ} \mathrm{C}\right)$ & 170 \\
\hline Gas Properties & Initial porosity, fraction & 0.13 \\
\hline Gas gravity & 0.684 & Initial water saturation, fraction & 0.2581 \\
\hline Pseudo-critical pressure ( MPa ) & 4.768 & Pore compressibility ( 1/Mpa ) & 0.000659 \\
\hline Pseudo-critical temperature ( K ) & 206.7 & Water compressibility ( 1/Mpa ) & 0.000698 \\
\hline \multicolumn{2}{|c|}{ Information } & Of Numerical Control \\
\hline Time step ( d ) & 30 & Pressure tolerance & 0.001 \\
\hline
\end{tabular}

First, we can fix geological reserves and initial reservoir pressure of the four blocks and make fitting analysis of the observed reservoir pressures after setting the transmissibility as the fitting parameter. Then, fitting analysis is made after geological reserves of all the blocks are set as the fitting parameter. When the sum of residuals squared of fitting is the smallest, we can obtain the fitting geological reserves and transmissibility. The results are shown in Table 5. Block A does not connect with block $\mathrm{C}$ and block D directly, so cumulative influx and transmissibility between them are 0 and they are not presented in the table below.

Table 5 Fitting results of all the blocks

\begin{tabular}{c|c|c|c|c}
\hline & Block A & Block B & Block C & Block D \\
\hline Fitting geological reserves, $10^{8} \mathrm{~m}^{3}$ & 300 & 200 & 38 & 21 \\
\hline $\begin{array}{c}\text { Remaining geological } \\
\text { reserves, } 10^{8} \mathrm{~m}^{3}\end{array}$ & 110.61 & 83.04 & 15.71 & 11.06 \\
\hline & $\begin{array}{c}\text { Block A - Block } \\
\text { B }\end{array}$ & $\begin{array}{c}\text { Block B - Block } \\
\text { C }\end{array}$ & $\begin{array}{c}\text { Block B - Block } \\
\text { D }\end{array}$ & $\begin{array}{c}\text { Block C - Block } \\
\text { D }\end{array}$ \\
\hline Cumulative gas influx, $10^{8} \mathrm{~m}^{3}$ & 107.65 & 1.06 & 6.96 & -0.41 \\
\hline Transmissibility, md.m & 2500 & 6 & 40 & 9 \\
\hline
\end{tabular}

Fig. 15 presents the fitting curves of reservoir pressure and it shows that the fitting results is rather satisfactory, demonstrating that this method is applicable to such an open type fault block gas reservoir. The sum of the residuals squared is $7.36 \mathrm{MPa}$ 。

The fault sealing is poor between block A and block B according to the results of the parameter estimations in Table 5. The history match resulted in a transmissibility of $2500 \mathrm{md} \cdot \mathrm{m}$ and a GIIP of 
block A of $300 \times 10^{8} \mathrm{~m}^{3}$ and block B of $200 \times 10^{8} \mathrm{~m}^{3}$. There was only X7 well in block B producing and it was shut in after production of a short time of five years. The remaining reserves are $83.04 \times 10^{8} \mathrm{~m}^{3}$, indicating that the producing reserves is large. Fig. 16 shows that instantaneous flow rate into block A decreased soon after commissioning of X7 well in block B in 2005. So the apparent formation pressure of both blocks tended to be equal. Then instantaneous flow rate increased gradually in 2011 after it was shut in due to water breakthrough.

The fault sealing is good between block B and block C as well as block D. The history match resulted in a small transmissibility of $6 \mathrm{md} \cdot \mathrm{m}$ and $40 \mathrm{md} \cdot \mathrm{m}$ respectively. Because of the small transmissibility, pseudo-steady flow did not develop between them after block B was put into production, so apparent formation pressure between them kept divergent. Fig.17 shows that instantaneous flow rate into block B decreased soon after commissioning of X13 well in block C in May, 2007. The apparent formation pressure of block $\mathrm{C}$ dropped rapidly and it was a little smaller than that of block B at the end of 2012. Therefore, block B supplied block C with gas. Fig.18 shows that instantaneous flow rate into block B decreased soon after commissioning of X12 well in block D in February, 2005. The apparent formation pressure of block D dropped rapidly. One year later, instantaneous flow rate increased gradually after X12 was shut in because of producing water.

The fault sealing is good between block $\mathrm{C}$ and block D. The history match resulted in a small transmissibility of $9 \mathrm{md} \cdot \mathrm{m}$. Because of the small transmissibility, pseudo-steady flow did not develop between them, so apparent formation pressure between them kept divergent. Fig.19 shows that instantaneous flow rate into block $\mathrm{C}$ decreased soon after commissioning of X13 well in block $\mathrm{C}$ in May, 2006. The apparent formation pressure of block $\mathrm{C}$ also dropped rapidly. However, X12 well in block D was shut in due to water breakthrough at the end of 2005, and then formation pressure of block D built up, leading to formation pressure of block D being larger than that of block C. Therefore, gas in block D flow into block $\mathrm{C}$.

In summary, GIIP of block B is almost employed so infilling well is not recommended. Although $\mathrm{X} 12$ well in block D was shut in due to water breakthrough, the results of the parameter estimations indicate that GIIP of block D is also employed.

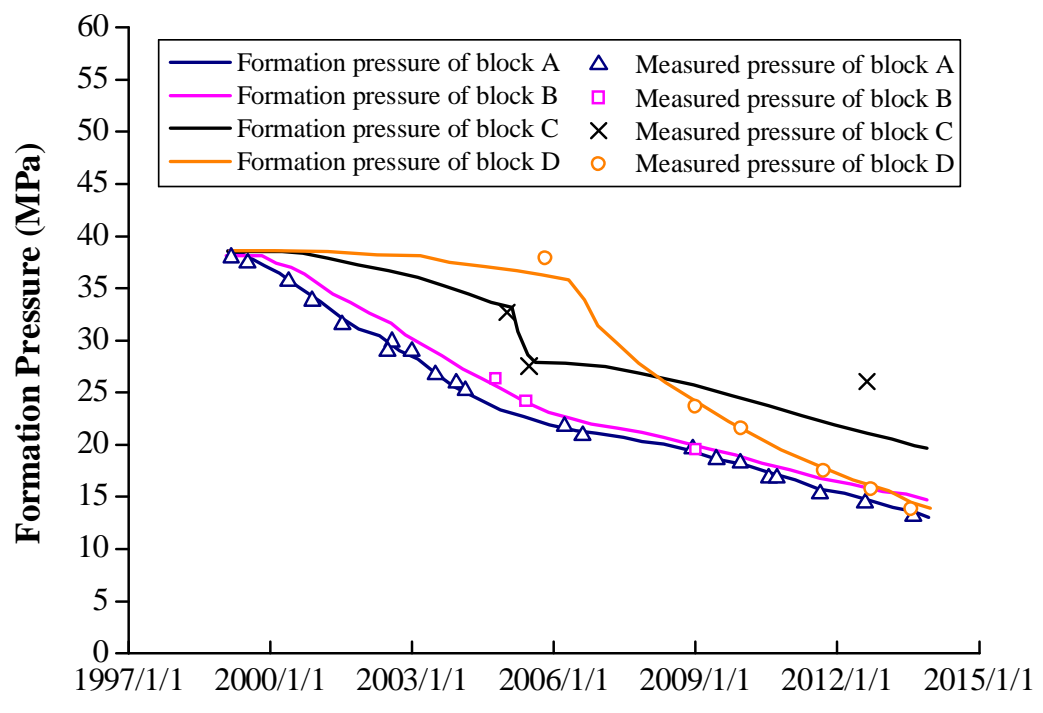

Date $(\mathbf{y y y y} / \mathbf{m} / \mathbf{d})$

Fig.15 History match of observed reservoir pressures in a certain complex fault gas reservoir 


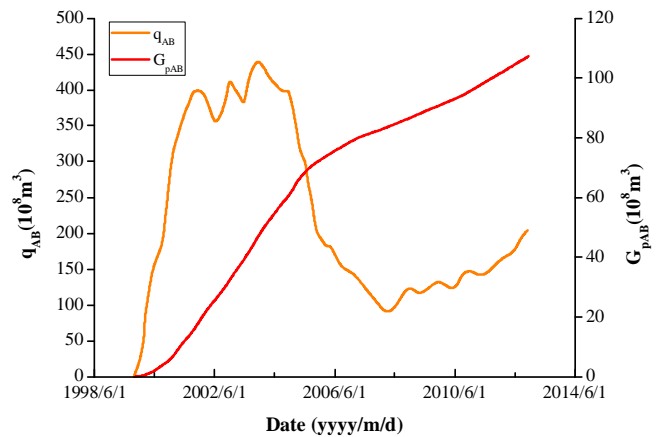

Fig.16 Influx into block A from block B

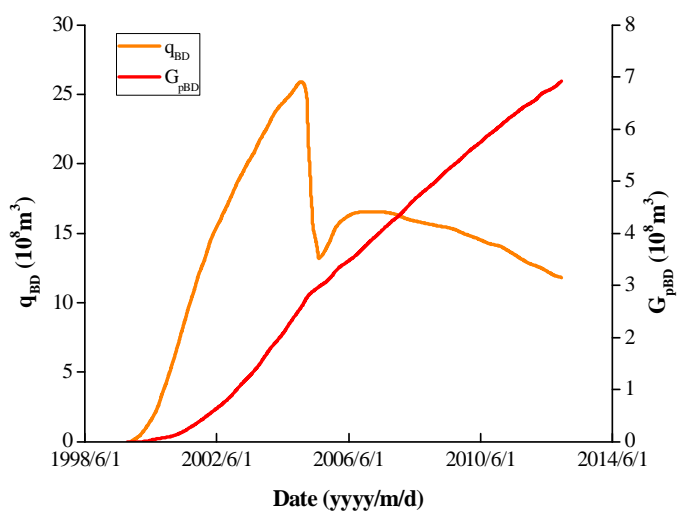

Fig.18 Influx into block B from block D

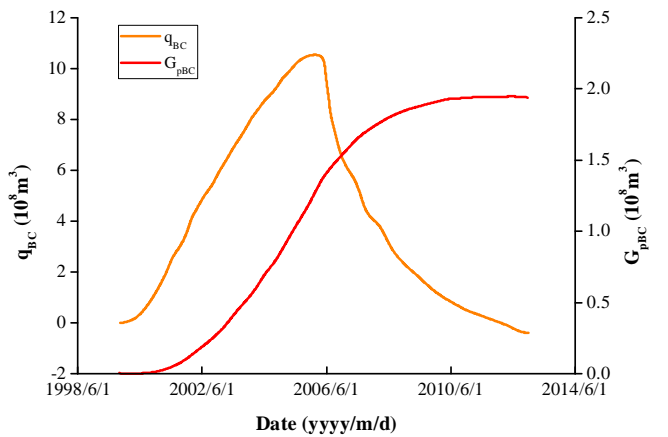

Fig.17 Influx into block B from block C

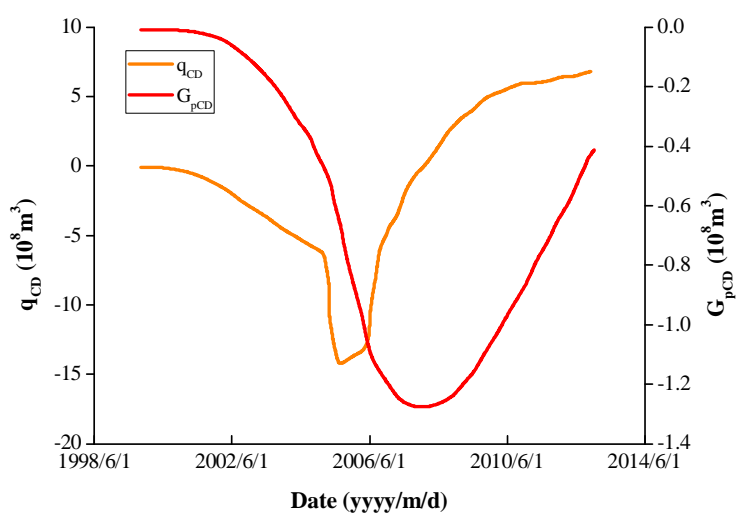

Fig.19 Influx into block C from block D

\section{Conclusions}

MBEs of multicompartment gas reservoirs were derived according to material balance. The determinations of the related physical parameters of gas were introduced.

Newton-Raphson iteration scheme was employed to solve the MBEs under successive time step. Computer programming proved this scheme is fast and steady. Pressure would converge within 3-8 iterations.

Aimed at the existence of influx and efflux in a complex, offshore fault block gas reservoir with four blocks, the MBEs of four-compartment gas reservoirs was applied to analyze change in influx and instantaneous flow rate of these blocks. History match of observed reservoir pressures was good, demonstrating that this method is applicable to such an open type fault block gas reservoir.

The results of the parameter estimations indicate that reserves of block B and block D were both employed, so there was no need to infill well. This would be helpful to reduce costs and improve economic efficiency.

\section{Nomenclature}

$G_{p i j}$ —cumulative gas influx from reservoir $\mathrm{j}$ into reservoir $\mathrm{i}, 10^{8} \mathrm{~m}^{3}$

$q_{i j}$-instantaneous gas flow rate from reservoir $\mathrm{j}$ into reservoir $\mathrm{i}, 10^{8} \mathrm{~m}^{3}$

$m_{j}$ - pseudo pressure corresponding to the average formation pressure of reservoir $\mathrm{j}, \mathrm{MPa} / \mathrm{mPa} \bullet \mathrm{s}$

$T_{r i j}$-transmissibility of fault between reservoir i and reservoir $\mathrm{j}, \mathrm{md} \cdot \mathrm{m}, T_{r i j}=K_{f i j} A_{f i j} / w_{f i j}$

$K_{f i j}$ - permeability of fault between reservoir i and reservoir j, md

$p_{j}$-formation pressure of reservoir $\mathrm{j}, \mathrm{MPa}$

$z_{j}$-Z-factor corresponding to the average formation pressure of reservoir $\mathrm{j}$, dimensionless 
$G_{p i}$ - cumulative gas production of reservoir $\mathrm{i}, 10^{8} \mathrm{~m}^{3}$

\section{References}

[1] Chen Fajing. Compaction and hydrocarbon migration. China University of Geosciences Press, 1989.

[2] T.L. Hower and R.E. Collins. Detecting Compartmentalization in Gas Reservoirs Through Production Performance[J].SPE19790,1989.

[3] M.E. Lord and R.E. Collins. Detecting Compartmented Gas Reservoirs Through Production Performance[J]. SPE22941,1991.

[4] Gao Chengtai. The material balance equation with a supplying region and its use in gas reservoir[J].Petroleum Expoloration and Development, 1993,20(2):53-61.

[5] Yang Ling, Gao Chengtai, Gao Weixin. Application of unbalance recovery to the gas field in central Shaanganning[J]. Journal of Xi' an Petroleum Institute: Natural Science Edition,1999,14(2):13-15.

[6] Gao Chengtai, Zhang Minyu, Yang Ling. A study of unbalanced development for closed gas reservoir[J].Acta Petrolei Sinica,1997,18(1):70-76.

[7] Gao Chengtai, Lu Tao, Gao Weixin, et al. Multi-region material balance method and its use in the performance prediction and optimal well pattern design of edge water reservoir[J].Petroleum Exploration and Development,2006,33(1):103-106.

[8] Payne D A. Material balance calculations in tight-gas reservoirs: the pitfalls of p/Z plots and a more accurate technique [J].SPERE, November, 1996:260.

[9] Jacques Hagoort. Numerical Solution of the Material Balance Equations of Compartmented Gas Reservoirs [J]. SPE57655, 1999.

[10] N.M.A. Rahman, and A.K. Ambastha. Generalized 3D Analytical Model for Transient Flow in Compartmentalized Reservoirs [J].SPE65106, 2000.

[11] Liu Fei, Lu Zhengyuan, Wang Qingkui. Reserve Calculation of Compartment Reservoirs. Petroleum Drilling Techniques, 2007.35(3):69-71.

[12] W.F. Leung. A Fast Convolution Method for Implementing Single-Porosity Finite/Infinite Aquifer Models for Water-Influx Calculations.SPERE.1986:490-510. 